\title{
A ACESSIBILIDADE NAS EMPRESAS: PERCEPÇÕES SOBRE A INCLUSÃO DE PESSOAS COM DEFICIÊNCIA NO MERCADO DE TRABALHO
}

\section{ACESSIBILITY IN BUSSINESS: PERCEPTIONS ON THE INCLUSION OF PEOPLE WITH DISABILITIES IN THE LABOR MARKET}

\author{
Aline Vieira Borges ${ }^{1}$, Esp. \\ Willians Cassiano Longen², Dr. \\ (1) Universidade do Extremo Sul Catarinense, UNESC \\ e-mail: alineborges.arq@hotmail.com \\ (2) Universidade do Extremo Sul Catarinense, UNESC \\ e-mail:wcl@unesc.net
}

Acessibilidade, Mercado de Trabalho, Pessoa com Deficiência

É garantido à pessoa com deficiência o acesso ao mercado de trabalho, de forma a desenvolver suas competências a fim de tornar-se útil e valorizada pela sociedade. No entanto, são observados grandes abismos entre o que é preconizado pela legislação e a realidade envolvendo a inclusão da pessoa com deficiência no mercado de trabalho. Desta forma, busca-se identificar condicionantes para a inserção de pessoas com deficiência $(\mathrm{PcD})$ ao trabalho por meio da análise de como este processo vem ocorrendo ao longo dos anos. Serão apresentadas as relações que as PcD têm estabelecido com a sociedade e o mercado de trabalho, permitindo assim, novas percepções e entendimentos acerca do tema explorado nesta pesquisa. Como resultados desta pesquisa buscou-se explorar as principais problemáticas envolvendo a acessibilidade nas empresas, bem como, direcionamentos vivenciados em diferentes centros, para atenção à legislação referente à inclusão da PcD no mercado de trabalho.

\section{Acessibility, Labor Market, Disable Person}

The disabled person is guaranteed access to the labor market in order to develop their skills in order to become useful and valued by society. However, there are large gaps between what is advocated by legislation and the reality involving the inclusion of people with disabilities in the labor market. In this way, we seek to identify conditions for the insertion of people with disabilities (PcD) to work by analyzing how this process has been occurring over the years. It will be presented the relations that the DCs have established with the society and the labor market, thus allowing, new perceptions and understandings about the theme explored in this research. As a result of this research, we sought to explore the main 
$16^{\circ}$ USIHC - Congresso Internacional de Ergonomia e Usabilidade de Interfaces Humano Computador

CINAHPA | 2017 - Congresso Internacional de Ambientes Hipermídia para Aprendizagem. problems involving accessibility in companies, as well as, orientations experienced in different centers,
for attention to the legislation regarding the inclusion of PCD in the labor market.

\section{Introdução}

A inclusão é parte do compromisso social de organizações públicas e privadas na promoção da diversidade, respeito às diferenças e garantia legal do acesso ao mercado de trabalho a todos os indivíduos.

No Brasil, é direito de todas as pessoas com deficiências (PcD's), assegurado pela Lei

Brasileira de Inclusão ( $\mathrm{n}^{\mathrm{O}} 13.146$, de 6 julho de 2015), bem como dos demais cidadãos, o acesso à vida, à habilitação e reabilitação, à saúde, à moradia e ao trabalho (BRASIL, 2015). O acesso ao trabalho é uma das principais formas de participação ativa na comunidade, além de garantia de igualdade dos direitos fundamentais.

Com o intuito de promover a inclusão do mercado de trabalho algumas leis foram sendo

estabelecidas, dentre as quais destaca-se a lei $\mathrm{n}^{\mathrm{O}}$ 8213/91 que, em seu artigo 93, descreve: "a empresa com 100 (cem) ou mais empregados está obrigada a preencher de $2 \%$ (dois por cento) a $5 \%$ dos seus cargos com beneficiários reabilitados ou com pessoas portadoras de deficiência, habilitadas, na seguinte proporção: I - até 200 empregados, $2 \%$; II - de 201 a 200, 3\%; III - de 501 a 1.000, 4\%; IV - de 1.001 em diante, 5\% (BRASIL, 1991).

Ainda neste sentido, dentre as recentes está a lei $\mathrm{n}^{\circ}$ 13.146, de 6 de julho de 2015, onde foi instituída a "Lei Brasileira de Inclusão da Pessoa com Deficiência (Estatuto da Pessoa com Deficiência), destinada a assegurar e a promover, em condições de igualdade, o exercício dos direitos e das liberdades fundamentais por pessoa com deficiência, visando à sua inclusão social e cidadania" (BRASIL, 2015).

No entanto, faz-se necessário salientar que a inclusão destas pessoas ao mercado de trabalho não deve estar pautada tão somente em números para o cumprimento da lei. A empresa, para que esta seja realmente inclusiva, precisa de ações que proporcionem a mudança, não somente na acessibilidade por meio da quebra de barreiras físicas, mas também no rompimento de preconceitos estabelecidos na atitude da sociedade em relação à pessoa com deficiência e na adequação do trabalho a condição do colaborador. (ETHOS, 2002).

A discussão acerca da inclusão e acessibilidade de pessoas portadoras de necessidades especiais no mercado de trabalho tem estado em constante evidência, desta forma, este estudo tem por objetivo identificar condicionantes para a inserção de pessoas com deficiência ao trabalho e analisar como este processo vem ocorrendo ao longo dos anos e quais as perspectivas para o rompimento das barreiras que prejudicam a inclusão social desta parcela da população.

\section{Discussão}

\subsection{A Construção Histórica da Pessoa com Deficiência e da Inclusão}

No decorrer da história, o contexto das pessoas com deficiências em relação à sociedade foi sendo gradualmente modificado, delineando um histórico que passa da invisibilidade projetada pela exclusão social até a busca atual e constante pela cidadania proporcionada pelo processo de inclusão que se almejar vivenciar.

Entre os povos primitivos, em decorrência do estilo de vida nômade, onde sua sobrevivência dependia da natureza e do habitual deslocamento, era necessário que cada membro pudesse contribuir para o grupo e subsistir individualmente. Desta forma, aqueles cujas características não correspondiam ao perfil considerado normal, sofriam um processo de seleção natural, sendo abandonados (BIANCHETTI, 2004).

Durante a da Antiguidade Clássica, período este marcado por importantes legados nas artes, ciências e nas leis, o tratamento destinado ás

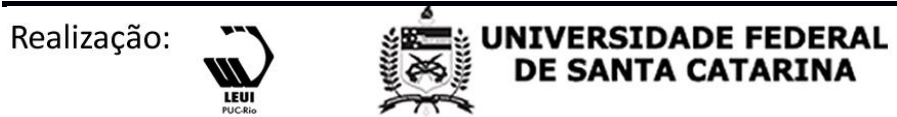




\section{$16^{\circ}$ \\ ERGODESIGN USIHC CINAHPA}

pessoas com deficiência era o sacrifício ou abandono, corroborando com o senso de valorização da beleza, da força e da perfeição. Neste período, medidas eugênicas radicais eram praticadas com desígnio de fortalecimento destas sociedades (DICHER, TREVISAM, 2014).

Já durante a Idade Média, as percepções sobre a pessoa com deficiência sofrem algumas mudanças, uma vez que estes passam a ter o direito à vida, mas, no entanto, estes indivíduos eram abandonados à sorte, buscando sua sobrevivência em uma sociedade contextualizada na ambivalência entre castigo e caridade (ARANHA, 2001).

Na Idade Moderna, período que representou significativas mudanças na relação da sociedade com a PcD, começou-se a buscar um discernimento maior sobre a natureza destas deficiências, permitindo caracterizá-las por sua natureza e não mais baseada em fatores transcendentais. No transcorrer destes anos, ocorreu ainda, a instauração de instituições destinadas ao tratamento da pessoa com deficiência, no entanto, os reais objetivos ainda se pautadas na exclusão destes indivíduos até que considerados como aptos ao regresso a sociedade (ARANHA, 2001).

Com o início da Idade Contemporânea, surge uma nova perspectiva para as pessoas com deficiência, embora ainda longe de uma efetiva integração, mas um novo olhar de responsabilidade foi direcionado a este grupo, possibilitando novas oportunidades educacionais, de trabalho, de direitos adquiridos e de interação social (LORENZO, 2016).

Com os avanços do século XX, a assistência destinada às pessoas com deficiência teve um substancial desenvolvimento, passando a serem objetos das discussões sociopolíticas mundiais.

Entretanto, faz-se necessário enfatizar que embora a problemática relacionada à inclusão da pessoa com deficiência na sociedade contemporânea estivesse em gradual transformação, não significa que estes deixaram de ser alvo de discriminação e preconceitos (LORENZO, 2016). $16^{\circ}$ Ergodesign - Congresso Internacional de Ergonomia e Usabilidade de Interfaces Humano Tecnológica: Produto, Informações Ambientes Construídos e Transporte

$16^{\circ}$ USIHC - Congresso Internacional de Ergonomia e Usabilidade de Interfaces Humano Computador

CINAHPA | 2017 - Congresso Internacional de Ambientes Hipermídia para Aprendizagem.

\subsection{Garantias Legais de Acesso ao Trabalho}

O direito à inclusão das pessoas com deficiências nas diversas esferas da sociedade vem sendo garantido e constantemente discutido por organismos e instituições que buscam promover o desenvolvimento íntegro da $\mathrm{PcD}$, bem como para a construção de relações inclusivas entre todos os indivíduos.

Neste sentido, a Declaração Universal dos Direitos Humanos assegura, por meio do seu artigo 23, o direito de acesso todas as pessoas ao trabalho, á condições satisfatória de trabalho e proteção contra o desemprego (ONU, DECLARAÇÃO DOS DIREITOS HUMANOS, 1948).

$\mathrm{Na}$ esfera nacional, este direito é assegurado por meio do artigo 7 da Constituição Federal do Brasil de 1988, referindo-se especificamente a relação entre trabalho e pessoa com deficiência, vetando quaisquer práticas discriminatórias alusiva a admissão e remuneração destes profissionais. Em 1989, é publicado, com bases na Constituição, a Lei Federal 7.853 que estabelece as diretrizes de ação da Política Nacional de Integração das pessoas com deficiências, com o objetivo de propor, acompanhar e fiscalizar os direitos garantidos a esta parcela da população (BRASIL, 1988; BRASIL, 1989).

Em julho de 1991, o Brasil instituiu outra iniciativa para ratificar o acesso da PcD ao mercado de trabalho, a Lei de Cotas, a qual estabelece a proporcionalidade de vagas a serem destinados a trabalhadores com deficiência em relação ao número de colaboradores. No entanto, apesar das exigências legais e direitos assegurados, a participação desta parcela da população no mercado ainda é pouca expressiva.

Em 2004, através do Decreto Federal 5.296 que regulamenta legislações anteriores, como a Lei 10.048/2000 e a Lei 10.098/2000 (Lei da Acessibilidade), caminhando num sentido mais atual da discussão sobre a inclusão, não apenas concedendo amenidades, mas sim, buscando o foco nas reais necessidades, capacidades e direito a igualdade da PcD (GARCIA, 2010).
Realização:

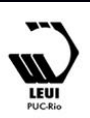




\section{$16^{\circ}$ \\ ERGODESIGN USIHC CINAHPA}

$16^{\circ}$ Ergodesign - Congresso Internacional de Ergonomia e Usabilidade de Interfaces Humano Tecnológica: Produto, Informações Ambientes Construídos e Transporte

$16^{\circ}$ USIHC - Congresso Internacional de Ergonomia e Usabilidade de Interfaces Humano Computador

CINAHPA | 2017 - Congresso Internacional de Ambientes Hipermídia para Aprendizagem.
No ano de 2015, as leis que garantem os direitos as pessoas com deficiência conquistam um grande avanço, após 15 anos em trâmites no Congresso Nacional, é aprovada em a Lei Brasileira de Inclusão passando a vigorar a partir de janeiro de 2016. Identificada ainda como Estatuto da Pessoa com Deficiência, a lei desperta um novo olhar sobre a PcD destinando-se a "assegurar e promover em condições de igualdade, o exercício dos direitos e das liberdades fundamentais por pessoa com deficiência, visando à sua inclusão social e cidadania" (BRASIL, Lei 13.146, 6 de julho de 2015. Art. 1).

Neste sentido, observa-se que inúmeras inovações e conquistas têm sido conquistadas no direito das PcD á uma sociedade inclusiva, no entanto, ainda existe diversas barreiras, não passíveis de garantias legais, que necessitam ser rompidas, principalmente no que se diz respeito aos relacionamentos interpessoais e nas relações de trabalho.

\subsection{O Papel das Empresas no processo de inclusão}

É fundamental que se busque desenvolver ações para trazer a diversidade para dentro das empresas, buscando desta forma, minimizar os efeitos do preconceito e da desigualdade, tornando nossas instituições mais inclusivas e acessíveis às pessoas com deficiências (ETHOS, 2002). Neste contexto, é imprescindível que se desenvolva a cultura da valorização da $\mathrm{PcD}$ no mercado de trabalho, ratificando a importância da implementação de um processo continuo de aprendizagem dentro das empresas.

Um importante paradigma a ser superado constante em relação ao papel das empresas no processo de inclusão é o foco direcionado ao cumprimento das cotas, conduzindo-os, muitas vezes, a resultados meramente quantitativos. É preciso ir além, viabilizando as $\mathrm{PcD}$ oportunidade que vão além de cargos operacionais, mas que possam estar se posicionando estrategicamente no mercado e com possibilidades de crescimento e desenvolvimento do seu intelecto (SCHWARZ, HABER, 2015).
Segundo dados do CENSO, 23,9\% possui algum tipo de deficiência, dentro deste percentual, destaca-se que 9 milhões de pessoas estão em idade de trabalho. No entanto, apenas $11,1 \%$ exercem alguma atividade remunerada e 2,2\% são colaboradores com registro em Carteira de Trabalho (IBGE, 2010).

Uma série de fatores são apontados como justificativas destes números de $\mathrm{PcD}$ em relação em mercado de trabalho, dentre os quais comumente se destacam a baixa escolaridade, descompromisso destes indivíduos com o trabalho, assiduidade. No entanto, a veracidade destas afirmações não retrata a realidade do cenário, onde indivíduos altamente qualificados encontram grandes limitações de se inserir no mercado por possuírem alguma deficiência. Desta forma, é importante ressaltar os ganhos da inclusão e das oportunidades de transformações que empresas inclusivas têm em suas mãos, contribuindo não somente para a sociedade na qual se insere, mas também, para um ambiente de trabalho colaborativo, produtivo e sinérgico.

No ambiente corporativo, ainda se observa muitas barreiras a serem dissociadas para a efetividade de um ambiente inclusivo, tanto arquitetônicas, no sentido de acessibilidade física, quanto atitudinais e culturais nos relacionamentos interpessoais no ambiente de trabalho.

Nesta perspectiva, uma grande oportunidade de experimentação da acessibilidade nas empresas é ouvir os envolvidos e trabalhar em conjunto, uma vez que o processo de inclusão é contínuo, que necessita ser constantemente aprimorado conforme as barreiras e os desafios surjam no dia a dia dos usuários.

\subsection{Acessibilidade e Adequação do Ambiente de Trabalho}

Além do desafio de conscientização da importância da inclusão de pessoas com deficiências no mercado de trabalho, uma série de barreiras precisam ser rompidas, sendo necessário um mapeamento da acessibilidade da empresa e um levantamento das adequações necessárias para o 


\section{$16^{\circ}$ \\ ERGODESIGN USIHC CINAHPA}

acesso e a condição adequada de trabalho a PcD (NEVES; PRAIS; SILVEIRA, 2015).

De acordo com a origem a deficiência, esta pode promover algumas restrições ao seu portador, o que gera dificuldades no acesso aos ambientes de trabalho, estas limitações físicas, ou barreiras arquitetônicas, não permitem a $\mathrm{PcD}$ exercer sua autonomia e potencialidades. Neste sentido, o ambiente da empresa deve ser repensado para a inclusão, conforme diretrizes estabelecidas pela Norma Técnica Brasileira (NBR 9050), dando condições de alcance, percepção e entendimento para utilização, com segurança e autonomia, por pessoa com deficiência ou mobilidade reduzida (NBR 9050, 2015).

Ao promover um ambiente livre de barreiras para as PcDs, sejam elas físicas, atitudinais, de informação, ou de acesso, a empresa oportuniza uma condição de trabalho mais funcional e segura ao colaborador, favorecendo ainda, sua permanência na instituição. É importante ressaltar que um ambiente livre de barreiras não é benéfico apenas para as pessoas com deficiências, mas para todos que compartilham destes espaços (ETHOS, 2002).

Ao considerar as condições do ambiente de trabalho é fundamental atentar-se ainda as estratégias ergonômicas que podem estar ampliando as relações de trabalho e psicofisiológicas dos colaboradores. Além das adequações físicas e atitudinais, a ergonomia contribuirá na viabilização de um ambiente acessível para as PcDs proporcionando conforto, autonomia e segurança no trabalho (ETHOS, 2002).

Desta forma, é imprescindível assumir que a acessibilidade e ergonomia são fatores essenciais na promoção de um desenvolvimento saudável, seguro e produtivo nas atividades exercidas pela PcD nas empresas, garantindo assim uma inclusão adequada. Desta forma, é de suma importância que as empresas, gestores e colaboradores em geral, assumam atitudes inclusivas, rompendo assim, com barreiras físicas e de preconceito, e que possam, portanto, reconhecer a $\mathrm{PcD}$ como um $16^{\circ}$ Ergodesign - Congresso Internacional de Ergonomia e Usabilidade de Interfaces Humano Tecnológica: Produto, Informações Ambientes Construídos e Transporte

$16^{\circ}$ USIHC - Congresso Internacional de Ergonomia e Usabilidade de Interfaces Humano Computador

CINAHPA | 2017 - Congresso Internacional de Ambientes Hipermídia para Aprendizagem.

profissional e parceiro no trabalho (NEVES; PRAIS; SILVEIRA, 2015).

\section{Considerações Finais}

A inclusão no mercado de trabalho deve ser cada vez mais incentivada pela sociedade, não estando pautada apenas no cumprimento da legislação, mas na transformação da cultura e no olhar sobre a pessoa com deficiência. A Lei de Cotas, bem como o Estatuto da Pessoa com Deficiência e demais leis que asseguram o direito destas pessoas são instrumentos fundamentais, no entanto, é preciso buscar um foco qualitativo nestas contratações, não apenas quantitativo.

O papel da gestão da empresa é imprescindível no processo de inclusão da pessoa com deficiência, proporcionando além da acessibilidade física, condições adequadas e seguras de trabalho, condição ergonômica favorável, igualdade de oportunidade com os demais.

Outro fator de importante relevância sobre a inclusão é o favorecimento para a desmitificação sobre a pessoa com deficiência. Estabelecer uma relação entre estes profissionais com o mercado de trabalho, possibilita exercer sua atividade laboral, dentro de suas limitações, mas de maneira eficaz, demonstrando o quão importante é o papel da $\mathrm{PcD}$ para o mercado.

A partir destas reflexões, pode-se afirmar que o torna uma empresa de fato inclusiva, está muito além do cumprimento da legislação, está pautada pelas atitudes diante da pessoa com deficiência, alinhando oportunidades dignas de trabalho, qualidade de vida e respeito às limitações de todas as pessoas. A inclusão é um desafio, por isso, é essencial que a empresa se reconheça neste processo e busque a promoção de um ambiente de trabalho que valorize a diversidade, dando a cada dia um novo passo em direção a inclusão e a novas conquistas em benefício das pessoas com deficiência.
Realização:

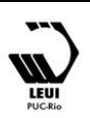


$16^{\circ}$ Ergodesign - Congresso Internacional de Ergonomia e Usabilidade de Interfaces Humano Tecnológica: Produto, Informações Ambientes Construídos e Transporte

$16^{\circ}$ USIHC - Congresso Internacional de Ergonomia e Usabilidade de Interfaces Humano Computador

CINAHPA | 2017 - Congresso Internacional de Ambientes Hipermídia para Aprendizagem.

\section{BIBLIOGRAFIA}

ABNT - Associação Brasileira de Normas Técnicas. NBR 9050. Acessibilidade a edificações, mobiliário, espaços e equipamentos urbanos. Rio de janeiro: ABNT. $3^{\text {a }}$ Edição. 2015.

ARANHA. M.S.F. Paradigmas da relação da sociedade com as pessoas com deficiência. In: Revista do Ministério Público do Trabalho, Ano XI, nº 21, 2001.

BIANCHETTI, Lucídio; FREIRE, Ida Mara. Um olhar sobre a diferença: interação, trabalho e cidadania. 6. ed Campinas, SP: Papirus, 2004.

BRASIL. Presidência da República. Casa Civil. Subchefia para Assuntos Jurídicos. Constituição da República Federativa do Brasil de 1988.

Disponível em:

<https://www.planalto.gov.br/ccivil_03/constituica o/constituicao.htm>. Acesso em: 28 nov. 2016.

. Presidência da República. Casa Civil.

Lei n. 7.853 de 24 de outubro de 1989. Disponível em:

<https://www.planalto.gov.br/ccivil_03/leis/L7853. htm>. Acesso em: 28 nov. 2016.

Presidência da República. Casa Civil. Lei n. 13.146 de 6 de julho de 2015. Disponível em:<http://www.planalto.gov.br/ccivil_03/_ato201 5- 2018/2015/Lei/L13146.htm>. Acesso em: 28 nov. 2016.

Presidência da República. Casa Civil. Decreto n. 5.296 de 2 de dezembro de 2004. Disponível em: <http://www.planalto.gov.br/ccivil_03/_ato20042006/2004/decreto/d5296.htm>. Acesso em: 28 nov. 2016.

DICHER, M.; TREVISAM, E. A jornada histórica da pessoa com deficiência: inclusão como exercício do direito à dignidade da pessoa humana. Disponível em

http://publicadireito.com.br/artigos/?cod=572f88de e7e2502b. Acesso em: 19 out. 2016.
ETHOS. O que as empresas podem fazer pela inclusão das pessoas com deficiência / coordenação Marta Gil. - São Paulo: Instituto Ethos, 2002.

GARCIA, V. G.. Pessoas com Deficiência e o Mercado de Trabalho: Histórico e Contexto Contemporâneo. 2010. 205 f. Tese (Doutorado) -

Curso de Economia, Instituto de Economia,

Unicamp, Campinas, 2010. Disponível em: $<$ http://www.bibliotecadigital.unicamp.br/docu men $t /$ ?code $=000782607>$. Acesso em: 28 nov. 2016.

IBGE. Censo Demográfico 2010 - Características Gerais da População. Resultados da Amostra. Disponível em: <http://censo2010.ibge.gov.br/resultados.html> Acesso em: 28 nov. 2016.

LORENZO, S. M. Inserção de pessoas com deficiências no mercado formal de trabalho a partir da percepção dos profissionais de recursos humanos das empresas. 2016. 138 f. Dissertação (Mestrado) - Curso de Educação, Programa de Pósgraduação em Educação, UNESP, Marília, 2016. Disponível em:

http://repositorio.unesp.br/handle/11449/136269. Acesso em: 14 nov. 2016.

NEVES P. S.; PRAIS F. G.; SILVEIRA A.M.Inclusão da pessoa com deficiência no mercado de trabalho em Belo Horizonte, Brasil: cenário e perspectiva. Ciênc. Saúde coletiva [online]. 2015, vol.20, n.8, pp.2549-2558. ISSN 1413-8123. Disponível em:

<http://www.scielo.br/scielo.php?pid=S141312320 $15000802549 \&$ script=sci_abstract\&tlng=pt $>$.

Acesso em: 28 nov. 2016.

SCHWARZ, A.; HABER, J. Instituto Ethos. Mercado de trabalho para pessoas com deficiência.2015. Disponível em: <https://www3.ethos.org.br/cedoc/ethosdireitos-humanos_mercado-de-trabalho-parapessoas-com- deficiencia/\#.WDxS6dUrLIU>. Acesso em: 28 nov. 2016.
Realização:

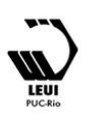

